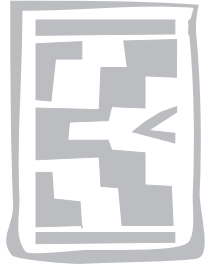

\title{
The helminth community of Helmeted Guineafowls, Numida meleagris (Linnaeus, 1758), in the north of Limpopo Province, South Africa
}

\author{
K. JUNKER ${ }^{1}$, L. DEBUSHO ${ }^{2}$ and J. BOOMKER ${ }^{1 *}$
}

\begin{abstract}
JUNKER, K., DEBUSHO, L. \& BOOMKER, J. 2008. The helminth community of Helmeted Guineafowls, Numida meleagris (Linnaeus, 1758), in the north of Limpopo Province, South Africa. Onderstepoort Journal of Veterinary Research, 75:225-235

The helminths of 15 Helmeted Guineafowls were collected in the north of Limpopo Province, South Africa. A total of 11 cestode, ten nematode and a single acanthocephalan species were present. Species richness ranged from 8 to 16 species per host, and nine core and nine secondary species accounted for $40.9 \%$ of the component parasite community. The remaining $18.2 \%$ comprised satellite species. Core species represented $91 \%$ of all the worms present. Individual intensities ranged from 66 to 2724 per host and overdispersion was pronounced. There were no significant differences regarding the abundance and species richness between male and female hosts. The number of component species and overall abundance did not differ significantly between juvenile and adult hosts, but Cyrnea parroti was significantly more abundant, and the prevalence of Hadjelia truncata was higher in young birds than in adults. In contrast, Gongylonema congolense and Porogynia paronai were absent in juveniles, but had a prevalence of $60 \%$ and $70 \%$, respectively, in adults. Pairwise Spearman's rank correlation yielded one positive and 10 negative significant species correlations. A single trematode, Dicrocoelium macrostomum, was collected from five of nine guineafowls, but was not included in the helminth community study.
\end{abstract}

Keywords: Acanthocephala, Cestoda, Helmeted Guineafowls, Nematoda, Numida meleagris

\section{INTRODUCTION}

Despite the remarkable diversity of South African birdlife, knowledge concerning their helminth parasites is scant (Ortlepp 1937, 1938a, b, 1963; VersterPatsinska-Kloryga 1987) and even sparser on the structure of their helminth communities.

A first step was taken by Crowe (1977), who compared the influence of sex, age and habitat on the

* Author to whom correspondence is to be directed. E-mail: joop.boomker@up.ac.za

1 Department of Veterinary Tropical Diseases, University of Pretoria, Private Bag X04, Onderstepoort, 0110 South Africa

2 Department of Statistics, University of Pretoria, Private Bag, South Africa

Accepted for publication 28 May 2008-Editor intestinal helminths of Helmeted Guineafowls, $\mathrm{Nu}$ mida meleagris (Linnaeus, 1758), at Kimberley, Northern Cape Province, South Africa. Thereafter, Alexander \& McLaughlin (1997) provided a comprehensive analysis of the helminth communities of four species of ducks at Barberspan, South Africa. It is also apparent from Bush's (1990) chapter on helminth communities in avian hosts, that considerably more information on helminth community dynamics in birds from aquatic environments than those from terrestrial habitats is available.

This paper analyses the composition and structure of the helminth community of 15 Helmeted Guineafowls in the Limpopo Province, even though small numbers of hosts were available and a larger sample might have a different outcome. Data on the various 
Helminth community of Helmeted Guineafowls in Limpopo Province, South Africa

helminth species collected have been presented in a companion publication (Junker \& Boomker 2007a).

\section{MATERIAL AND METHODS}

During July 2005 to November 2006 the gastrointestinal helminths of 15 Helmeted Guineafowls on a farm about $60 \mathrm{~km}$ west of Musina (Messina), Limpopo Province (22 $22^{\circ} \mathrm{S}, 29^{\circ} 30^{\prime} \mathrm{E}$ ), were examined as detailed in Junker \& Boomker (2007a). Three of the birds shot in May 2006 and two collected in July 2006 were young birds, between 6 and 10 months old (Siegfried 1966), the remainder were adults. Three of the juveniles were females and two males, and the adults comprised four females and six males.

The terms prevalence, intensity and abundance are used in accordance with the proposals of Margolis, Esch, Holmes, Kuris \& Schad (1982) and Bush, Lafferty, Lotz \& Shostak (1997). Infrapopulation and infracommunity follow Bush \& Holmes (1986a, b), metapopulation follows Riggs \& Esch (1987) and component parasite community is used as defined by Holmes \& Price (1986). As suggested by Bush \& Holmes (1986a) and Alexander \& McLaughlin (1997), species with a prevalence of $70 \%$ and higher, were categorized as core species, those with prevalences of $<40 \%$ as satellite species and those with prevalences $\geq 40 \%$ but $<70 \%$ as secondary species. A summary of these definitions is to be found in Esch, Shostak, Marcogliese \& Goater (1990).

A Wilcoxon rank sum test was performed to determine differences in species richness, as well as in the abundance of the various species between male and female hosts, juveniles and adults and between birds shot in winter and spring. A variance ratio test of Schluter (1984) and McCulloch (1985) was used to detect species association with presence-absence data for all parasites, parasites in the small intestine (SI) and parasites in the caeca.

Pairwise Spearman's rank correlation for every possible species combination in the small intestine, gizzard and caeca respectively were calculated. To avoid possible distortions inherent to this form of analysis, double zero matches, i.e. absence of both species from a host, were eliminated. Of the 14 helminth species present in the small intestine only the single acanthocephalan and the 12 cestodes were included in the analysis, because the occurrence of two nematodes, Ascaridia numidae and an unidentified subulurid, was restricted to one and two hosts respectively, while a third nematode, Sicarius caudatus, utilized the SI as well as the gizzard. We tested for a correlation between Subulura dentigera and Subulura suctoria from the caeca only, as Subulura sp. most probably represents either of the former two nematodes.

Significance was set at the $95 \%$ level throughout. In the absence of scoleces, counts were not always possible for all the cestodes of a particular host. While these hosts were included in analyses based on presence/absence data, they were excluded from the sample pool in the Wilcoxon rank sum tests pertaining to the abundance of helminths at species level.

\section{RESULTS}

A total of 11951 helminths representing ten nematode, 11 cestode and a single acanthocephalan species were recovered from the alimentary canal of the 15 guineafowls. Data on their prevalence, intensity of infection and abundance, as well as their feeding guild classification and status as core, secondary or satellite species are summarized in Table 1. In all likelihood, Raillietina sp. and Subulura sp. are representatives of the remaining species of these two genera listed in Table 1. A single trematode species, Dicrocoelium macrostomum, was present in five of nine guineafowls examined for this parasite. Although included in the general results and discussion, these trematodes do not form part of the community study outlined below.

Following the classification of Bush (1990) four feeding guilds, i.e. organisms using the same feedingmode, without regard to their taxonomic affinity, were present in the helminth community. The trematode guild, feeding actively on semi-solid food materials such as blood, bile, mucus and intestinal debris as well as directly absorbing nutrients through their tegumental surface, was restricted to the liver and represented by a single species. The nematode guild, being mucosal and engulfing tissue and/or lumen contents, occupied the largest number of sites along the alimentary canal, namely the crop, proventriculus, gizzard as well as the small and large intestine. The females of Tetrameres numida are an exception in so far as they inhabit the glands of the proventriculus, where they suck blood.

The cestodes and acanthocephalans occurred in the small intestine only. Mediorhynchus gallinarum has a short neck and its attachment to the mucosa remains superficial. The larger part of its abdomen is suspended freely in the intestinal lumen, absorbing nutrients via the body surface (Junker \& Boomker 


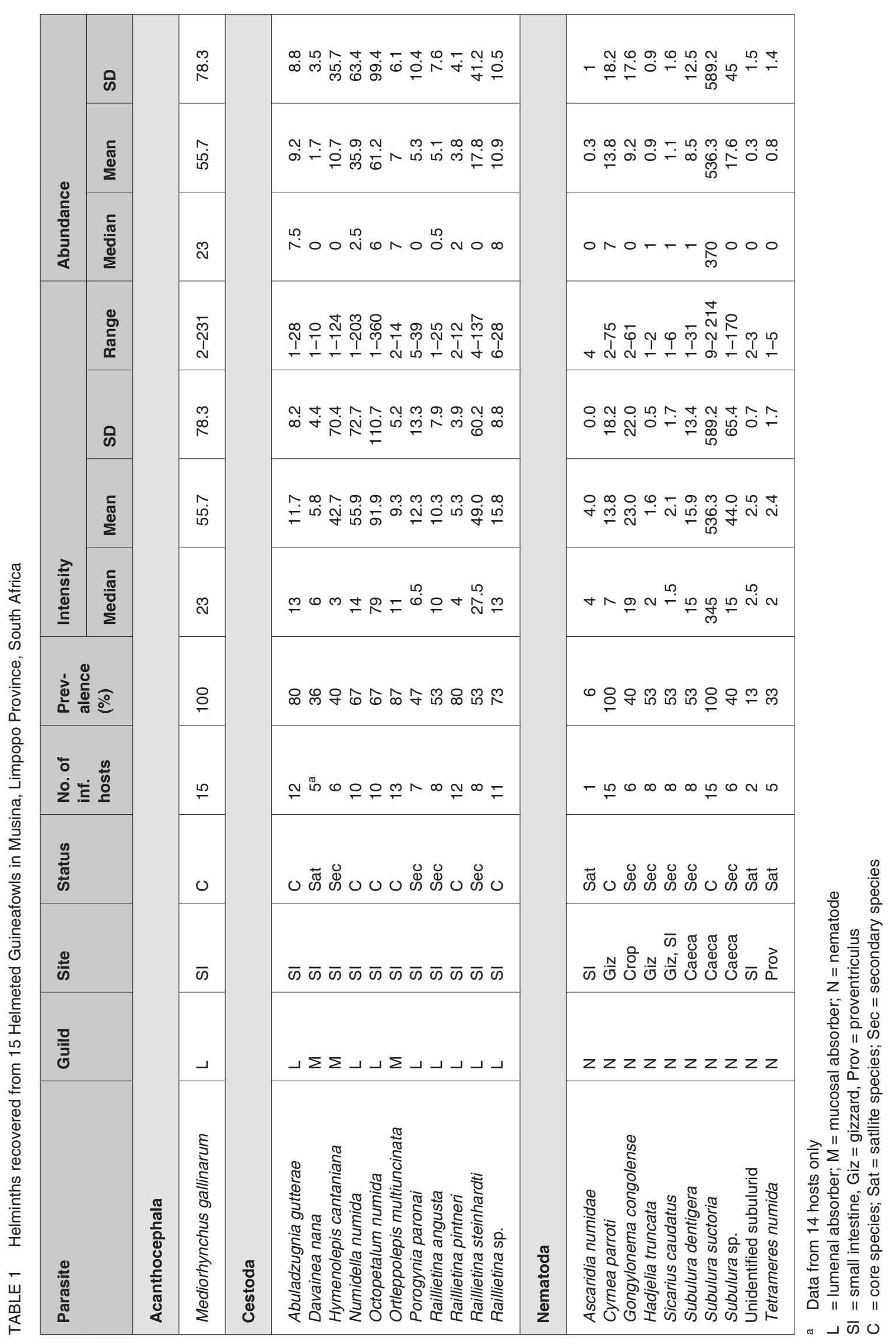


2006). It is therefore included in Bush's (1990) category of lumenal absorbers, together with the majority of the larger cestodes. Small and delicate cestodes such as Davainea nana, Hymenolepis cantaniana and Ortleppolepis multiuncinata, whose entire body is virtually buried amongst the mucosal villi, constitute the fourth guild, namely that of mucosal absorbers.

Except for the monoxenous nematode Ascaridia numidae, all members of the component community have indirect life-cycles.

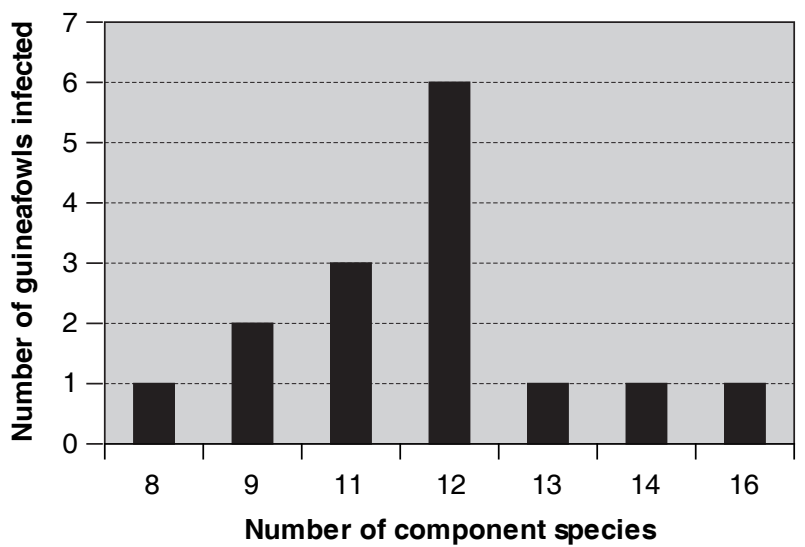

FIG. 1 Frequency distribution of the total number of helminth species found in Helmeted Guineafowls in Musina, Limpopo Province, South Africa. The number of individual hosts infected by a certain number of helminth species is indicated by the vertical bars
The component community comprised nine core species as well as nine secondary species, each representing $40.9 \%$ of the total number of species, and four satellite species accounting for $18.2 \%$ of the species present (Table 1). Despite their prevalence of $67 \%$ being slightly below the $70 \%$ threshold, we have arbitrarily included Numidella numida and Octopetalum numida with the core species, as they were two of the most numerous helminths recovered in this study. The core species accounted for $91 \%$ of all individuals, the secondary species for

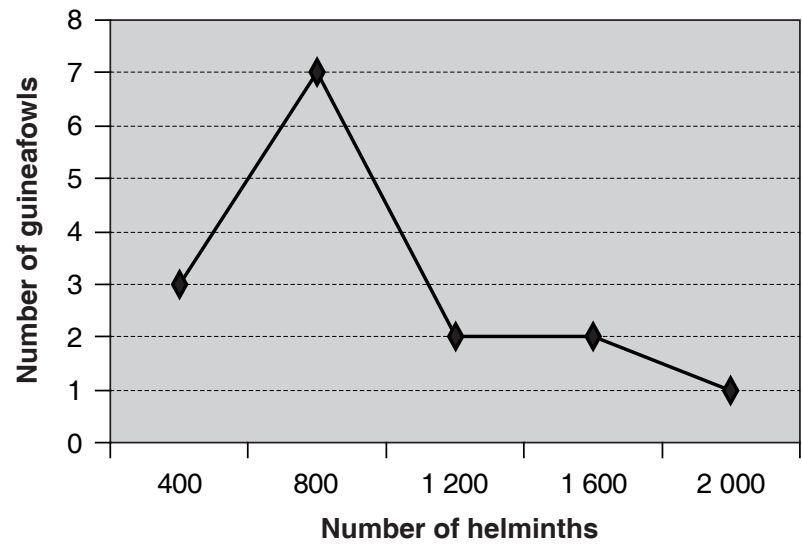

FIG. 2 The frequency distribution of the total number of helminths in individual Helmeted Guineafowls in Musina. Helminth burdens were grouped into size classes $(0-$ $400,401-800$, etc. to $2000+$ helminths per guineafowl) represented on the $x$-axis. The $y$-axis displays the number of guineafowls infected with a certain size class of helminth burdens

TABLE 2 Number of helminth species recovered from 15 Helmeted Guineafowls in Musina, Limpopo Province, South Africa

\begin{tabular}{|l|l|l|l|l|}
\hline \multirow{2}{*}{ Host } & \multicolumn{2}{l}{ Number of species } & Total number of \\
& Acanthocephalans & Cestodes & Nematodes & species \\
\hline GFM1 & 1 & 9 & 6 & 16 \\
GFM2 & 1 & 7 & 4 & 12 \\
GFM3 & 1 & 7 & 5 & 13 \\
GFM4 & 1 & 7 & 4 & 12 \\
GFM5 & 1 & 4 & 4 & 9 \\
GFM6 & 1 & 5 & 6 & 12 \\
GFM7 & 1 & 5 & 3 & 9 \\
GFM8 & 1 & 5 & 6 & 12 \\
GFM9 & 1 & 5 & 5 & 11 \\
GFM10 & 1 & 5 & 2 & 8 \\
GFM11 & 1 & 5 & 5 & 14 \\
GFM12 & 1 & 6 & 3 & 12 \\
GFM13 & 1 & 7 & 5 & 11 \\
GFM14 & 1 & 5 & 5 & 11 \\
GFM15 & 1 & 6 & 4.5 & 12 \\
\hline Average & 1 & 6.1 & 1.2 & 11.6 \\
\hline SD & 0 & 1.4 & $2-6$ & 2.0 \\
\hline Range & 1 & $5-9$ & & $8-16$ \\
\hline
\end{tabular}




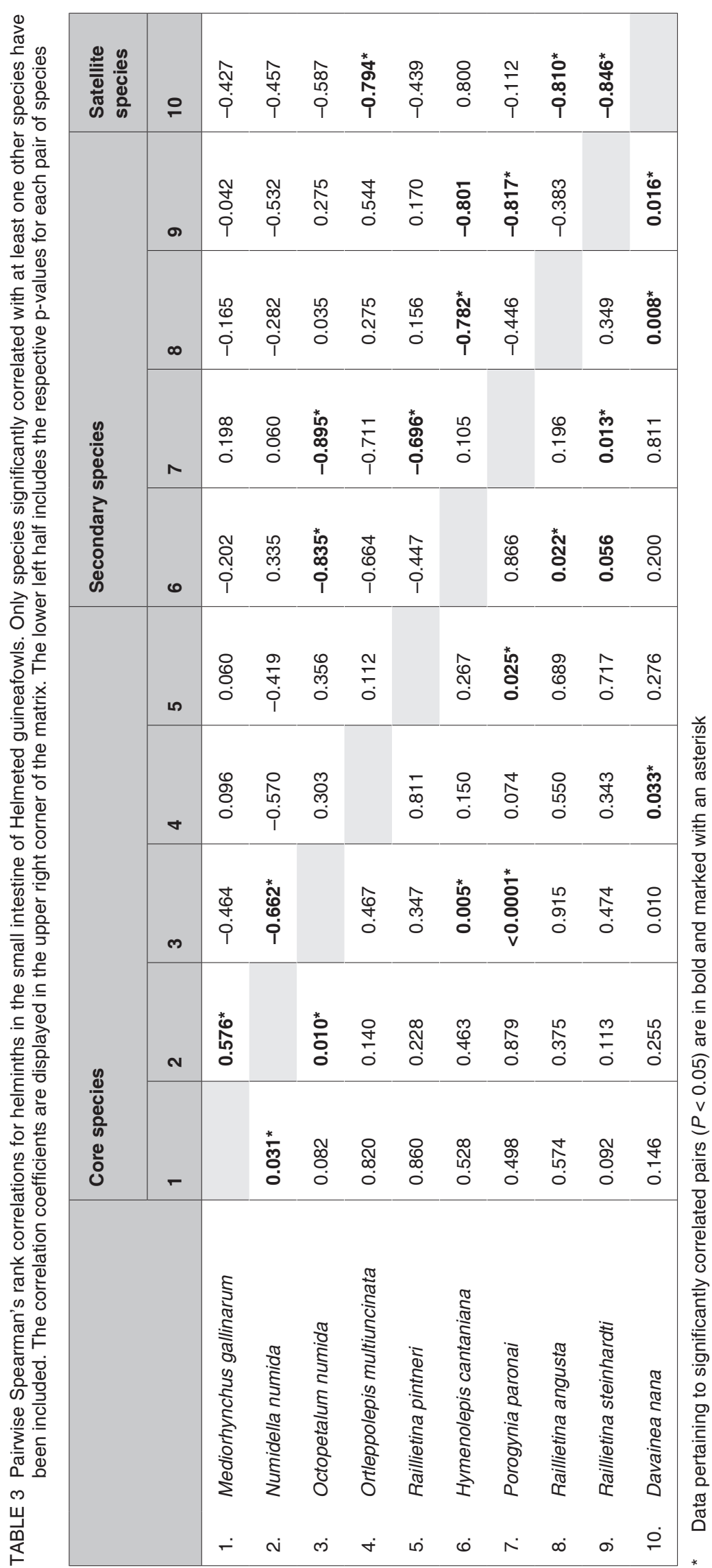


$8.6 \%$ and satellite species made up $0.4 \%$ of the total worm count.

Infracommunities in the Helmeted Guineafowls from Musina were moderately species rich, ranging from 8 to 16 species, with a mean number of $11.6 \pm 2$. Sixty percent of the hosts were infected with 12 or more species (Table 2, Fig. 1). The total number of helminths in individual guineafowls was highly aggregated and ranged from 66 to 2724 . In ten of the 15 hosts the intensity of infection was below 800 (Fig. 2), but three guineafowls had worm burdens of 1457,1496 and 2724 worms and when combined, these accounted for $48 \%$ of the component parasite community. Subulura suctoria, which was by far the most common of all the helminths recovered, constituted 86,74 and $81 \%$ of the total worm load of the above three hosts.

Excluding $S$. suctoria, the acanthocephalans and cestodes, especially $O$. numida and $N$. numida, occurred in higher numbers than nematodes. Cyrnea parroti, Gongylonema congolense, S. dentigera and Subulura sp. were moderately abundant with occasional high numbers in individual hosts. The abundance of the remaining nematodes was low, ranging from one to six in single hosts.

The Wilcoxon rank sum test yielded no significant evidence of differences between male and female hosts or between the winter and spring season in respect of species richness.

Despite the group of five juvenile Helmeted Guineafowls including the two birds with the lowest number of helminth species, and three of the five birds harboured a lower than average number of helminths, no significant differences were found between the number of component species and overall abundance seen in juvenile versus adult hosts.

However, when the Wilcoxon rank sum test was performed at species level, some differences related to host age became apparent. Of the gizzard nematodes, the abundance of $C$. parroti was significantly higher in young guineafowls, averaging $26.4 \pm 27.7$, than in adults, in which the mean abundance was $7.5 \pm 6.6(P=0.0312)$, and, although not statistically significant, the prevalence of Hadjelia truncata was twice as high in young birds than in older ones ( $80 \%$ vs $40 \%$ ). Conversely, Gongylonema congolense from the crop was absent in young birds, but had a prevalence of $60 \%$ in adult guineafowls. The abundance of this parasite was thus significantly higher in adults $(P=0.0451)$. Similarly, the cestode Porogynia paronai occurred in $70 \%$ of the adult birds, but was not found in the juveniles. Therefore, its abundance was significantly lower in the latter hosts $(P=0.032)$. The abundance of Subulura sp. was significantly higher in juvenile birds than in adults $(P=$ 0.0156).

The pairwise Spearman's rank correlation test yielded 11 significantly correlated species pairs in the small intestine, of which one was positive and 10 negative. The results are presented in Table 3 . The gizzard nematodes, $C$. parroti and $H$. truncata, were positively correlated, whereas $S$. dentigera and $S$. suctoria from the caeca were negatively correlated. Both results were, however, not significant.

\section{DISCUSSION}

Helmeted Guineafowls are non-selective omnivores feeding on a large variety of dietary items that, among others, include arthropods. Saayman (1966) recovered a wide variety of prey taxa, namely Orthoptera (four families), Coleoptera (five families), Isoptera, Hemiptera, Lepidoptera, Hymenoptera, Diptera, Myriapoda and Araneida, from the crops of 36 Helmeted Guineafowls in the Eastern Cape Province.

Notwithstanding their being a sedentary species, the birds can cover a considerable distance during their daily forays (Del Hoyo, Elliot \& Sargatal 1994). These characteristics and a well structured, complex alimentary canal are among the major host factors contributing to parasite community richness (Kennedy, Bush \& Aho 1986). This might explain why, despite the harsh climatic conditions and the largely undiversified mopani (Colophospermum mopane) veld habitat of the study area (Acocks 1988), the helminth community of Helmeted Guineafowls from Musina is diverse. The inclusion of live food in their diet, up to $12 \%$ of the annual total, but higher during the summer months when insects are abundant (Mentis, Poggenpoel \& Maguire 1975), may also account for the dominance of helminths with an indirect life cycle in the guineafowls.

We attribute the low prevalence and intensity of $D$. nana and especially of $A$. numidae to the arid environment characteristic of the study area. Ascaridia spp. were also the only nematodes with a direct life cycle recovered from guineafowls by Verster \& Ptasinska-Kloryga (1987). Their eggs are resistant and can survive for several months in suitable moist soil conditions (Anderson 1992), but these were certainly not met in the present study area. Furthermore, earthworms can harbour eggs and larvae, thus serv- 
ing as paratenic hosts (Anderson 1992), but environmental conditions were not conducive for this route of transmission either. No information is available as to the intermediate hosts of $D$. nana, but we assume that they are similar to those used by the congeneric Davainea proglottina, namely snails and slugs (Anderson 1992). Little evidence of these invertebrates was seen in or around water troughs and one would not expect them to occur in large number under the prevailing conditions. Thus, despite the high numbers of available final hosts, the scarcity of intermediate hosts seems to limit these parasites.

Similarly, the absence of the trematode guild from the small intestine of the guineafowls appears to be related to the availability of intermediate hosts. Most digeneans are dependant on molluscs or very rarely an annelid intermediate host for completion of their life cycles (Gibbons, Jones \& Khalil 1996). Hence, they are more frequently associated with an aquatic habitat. Hodasi $(1969,1976)$ concluded that trematodes were rare parasites in gallinaceous birds.

It is difficult to determine the host specificity of helminths, and whether a certain parasite is regarded as a specialist or a generalist is often subjective, especially as helminths which are specialists in a certain host can nevertheless occur in other, often related hosts (Bush 1990). Based on the host-parasite check list of guineafowls of Junker \& Boomker (2007b), we consider the following helminths as generalists: S. suctoria, $G$. congolense, $H$. truncata and possibly $A$. numidae as well as the cestode $H$. cantaniana and the acanthocephalan M. gallinarum. Each of these has been reported from a variety of hosts.

Many of the remaining helminths collected during this study are currently recorded from the guineafowl genera Numida and/or Guttera only, such as the nematodes $S$. dentigera and $T$. numida or the cestodes $O$. numida, Raillietina angusta, Raillietina pintneri and Raillietina steinhardti. Numidella numida which is equally common in guineafowls in the USA was also found in turkeys and domestic chickens in that country. However, failure to experimentally infect the latter hosts with the parasite (Jones 1933) led Reid (1962) to believe that chickens and turkeys were not natural hosts. While $S$. dentigera, T. numida, N. numida, O. numida, $R$. angusta, $R$. pintneri and $R$. steinhardti would therefore seem to be specialists in guineafowls, this, at best tentative, classification might simply reflect a general lack of data and could well change as more information on other gamebirds, such as korhaans, bustards, francolins, spurfowls and quails, becomes available. In an environment where high temperatures combined with low rainfall jeopardize successful completion of helminth life cycles, spreading the risk of transmission between various final hosts would appear a more reliable way to assure high parasite survival rates than a specialist approach. We would therefore expect the generalists to outweigh the specialists.

Similarly, helminths collected from the guineafowls in this study use a wide range of intermediate hosts and are often not limited to a specific host or even host taxon. Numidella numida, for example, is reported to use ground and dung beetles as well as grasshoppers (Reid 1962), and the common nematode, S. suctoria makes use of coleopterans, dermapterans and orthopterans (Anderson 1992). This strategy of spreading the risk of transmission between several intermediate hosts, all serving as prey to the final host, might well explain the aforementioned helminths' success in colonizing their final hosts, resulting in a prevalence of $100 \%$ in S. suctoria, even under adverse environmental conditions. However, intermediate host data are usually very generalized in respect of the taxonomic status of the hosts. Hence, as more life cycle data become available especially elucidating parasite-intermediate host associations at species level, this picture of lack of specificity might change.

The aggregated pattern of dispersion seen in our data is common in parasite communities (Pielou 1974; Bush \& Holmes 1986a, b; Alexander \& McLaughlin 1997) and is a result of a number of factors, such as differences in the individual host's immune competence, feeding preferences and species specific host behaviour (Petney, Van Ark \& Spickett 1990; Horak \& Boomker 2000). Saayman (1966) demonstrated a pronounced difference in feeding-preferences between different members of the same guineafowl flock both in the amount of food consumed as well as the composition of crop contents. The higher the food intake and the higher the percentage of insect matter in the individual's diet, the higher the probability of ingesting an infected intermediate host and becoming infected.

A further reason for the aggregation of helminths in certain host individuals is the fact that a single infected guineafowl can excrete hundreds of nematode eggs in its faeces and a single tapeworm proglottid can contain hundreds of hexacanth larvae. Consequently, dung beetles, or other insects, feed- 
ing on contaminated faeces or around contaminated patches can be exposed to large numbers of parasite eggs during a single meal. Reid (1962) records up to 50 cysticercoids of $N$. numida in infected intermediate hosts, up to 930 cysticercoids of Skrjabinia cesticillus were present in a single beetle, while dung beetles have been found to contain 100 or more cysticercoids of $H$. cantaniana. Thus the ingestion of a single infected intermediate host can lead to the presence of a large number of helminths in individual final hosts.

Nine core species were identified within the helminth community of Helmeted Guineafowls at Musina. The helminth infracommunity of a single Crested Guineafowl, Guttera edouardi, from a nearby locality examined by Junker \& Boomker (2007a) suggests a considerable overlap between the two parasite communities. Nine helminth species were present in the Crested Guineafowl, of which seven are core species and two are secondary species in Helmeted Guineafowls. This can probably be attributed to much the same feeding habits, exposing them to a similar pool of intermediate arthropod hosts.

Core species are usually the first to appear in juvenile birds (Hair 1975) and our data reflect the high colonization ability of these species, in that their proportional density in juvenile birds was distinctly higher than that seen in the overall host population $(60.6 \%$ vs $40.9 \%)$. In contrast, the percentage of secondary species in juvenile birds was $34.8 \%$ compared to $40.9 \%$ in the overall population, and satellite species averaged $4.6 \%$ in comparison with an overall average of $18.2 \%$.

Pairwise Spearman's rank correlation detected 11 significant correlations between helminth species in the small intestine. Of these, the only significant positive correlation occurred between the acanthocephalan $M$. gallinarum and the cestode $N$. numida, in that their intensities increased or decreased in unison. Positive associations between species can be due to several factors, amongst others the use of a common intermediate host. In this case a positive association in the source community would merely be transferred to the target community and would not necessarily reflect an interaction of the two species in the final host (Lotz \& Font 1994). As is the case with many of the other parasite species collected in our study, there is no data on the intermediate hosts used by M. gallinarum in South Africa. Its North American counterpart, Mediorhynchus grandis, however, has been reported to use several species of grasshoppers as intermediate hosts (Moore 1962), and grasshoppers also form part of the life cycle of $N$. numida (Mohler 1936; Reid 1962). Whether a source community is the origin of the positive correlation between these two species, or if one parasite indeed changes the habitat in the final host in such a way as to facilitate the colonization by the other, would necessitate experimental studies. Conversely, $N$. numida had a significant negative correlation with $O$. numida, which also uses orthopterans as intermediate hosts (Gwyun \& Hamilton 1935), and O. numida was negatively, albeit not significantly so, correlated with $M$. gallinarum.

Another positive correlation, although not significant $(P=0.0819)$, was found between $C$. parroti and $H$. truncata in the gizzard. The few data available on their intermediate hosts suggest that these do not overlap. Cyrnea parroti has been reported from orthopteran intermediate hosts and $H$. truncata from beetles (Anderson 1992). Their positive correlation might be a result of the fact that both seem to make use of a window period during the development of their host in which the latter is more susceptible to infection (see below).

Negative correlations between species, where an increased intensity of the one leads to a decreased intensity of the other, may result from competition for resources such as carbohydrates or attachment sites (Smyth \& McManus 1989). Or it could indicate that the presence of one species alters the habitat to such an extent that it is less suitable for the other. Smyth \& McManus (1989) report a number of substances that are produced by Hymenolepis diminuta and which might act as inhibitory factors, producing a crowding effect. Moreover, the host's immune response triggered by a certain species could well make this host less susceptible to subsequent colonization by other parasites.

Some of the factors influencing parasite community patterns in other hosts seem to be of little importance in structuring the helminth communities of Helmeted Guineafowls. One of these is age. Moore, Freehling, Horton \& Simberloff (1987) concluded that age can occasionally have an important influence on the prevalence and intensity of helminth infections of Bobwhite Quail, Colinus virginianus (Linnaeus, 1758), and Pence (1990) reported changes in host age over seasons to be one of the factors most frequently cited when discussing prevalence and intensity. However, in the present study neither overall abundance nor species richness in juvenile guineafowls differed significantly from those in adults.

In contrast, Crowe (1977) reported that juvenile Helmeted Guineafowls, i.e. birds younger than 10 
months, from the Kimberley district, South Africa had significantly higher burdens of cestodes and acanthocephalans than adults, and Davies, Junker, Jansen, Crowe \& Boomker (in preparation) found higher burdens of $S$. suctoria, $O$. numida and $M$. gallinarum in juveniles during a study on Helmeted Guineafowls in the Free State Province. Forrester, Conti, Bush, Campbell \& Frohlich (1984) found no significance in the differences between the prevalence of helminth species in chick and adult bobwhites, but the intensity of infection of a single helminth species was higher in chicks than in adults. When studying the helminth communities in willets, Tringa semipalmatus (Gmelin, 1789) (= Catoptrophorus semipalmatus), both on their breeding grounds (freshwater) and in their wintering habitat (saltwater), Bush (1990) found young birds to be depauperate, but within the course of 2 weeks the diversity of their helminth communities increased considerably and, in the case of helminths with freshwater life cycles, at 3 months of age no longer differed from those of adult birds.

Several factors could influence the prevalence and intensity of helminths in guineafowls of different ages. Young birds might well be more susceptible to helminth infections when compared to adults, as has been suggested by a number of authors (Ackert \& Reid 1937; Biester \& Schwarte 1959; Soulsby, 1969). However, this would be counterbalanced by a time-dependant higher probability of previous exposure to infected intermediate hosts, and thus to the various parasites, in older birds, therefore evening out differences between different ages on component community level. On the other hand, it is well documented that the diet of juvenile Helmeted Guineafowls and other gamebirds consists of a larger percentage of arthropods than that of adults (Del Hoyo et al. 1994; Crowe 2000), increasing their exposure to possible intermediate hosts.

Some age-related differences on metapopulation level, i.e. when singling out certain parasite species from the Musina hosts, were observed. Cyrnea parroti, whose predilection site is under the lining of the gizzard, was significantly more abundant in juvenile birds. We observed a distinct hardening of the gizzard lining in adult guineafowls which was not nearly as pronounced in the younger birds and which could easily impede establishment of this parasite in older hosts. This phenomenon might also explain why the prevalence of $\mathrm{H}$. truncata, using the same site, decreased from $80 \%$ in juveniles to only $40 \%$ in older guineafowls. Dogiel (1964) suggested that the normal development of a host, such as a thicken- ing of skin, could result in a habitat being no longer suitable for the parasite, hence leading to resistance against the latter.

The same mechanism is obviously not in play with G. congolense, which lives in tunnels under the crop mucosa. While the observed thickening of the mucosa should make colonization with $G$. congolense more difficult with increasing host age, this parasite was not found in any of the younger birds, but was present in $60 \%$ of the older hosts. A possible explanation might be that $G$. congolense is only a secondary species indicating that its prevalence in the entire ecosystem is lower than that of a core species such as $C$. parroti. Consequently, age, if seen as an increase of the probability of prior exposure to a certain parasite with time, might have a more pronounced influence on the distribution pattern of this particular parasite. Using the same reasoning, one could expect the prevalence of $H$. truncata, also a secondary species, to increase in adult birds. As has been discussed this is not the case. However, the hardening of the crop mucosa never seems as pronounced as that of the gizzard's and, while the latter would seem likely to form a suitable barrier against the establishment of parasites, this is not necessarily so in the former.

Similarly to $C$. congolense, the cestode $P$. paronai had a significantly higher abundance in adult guineafowls, being absent in young birds. Little is known about the life cycle of this parasite except that it is one of the cestodes making use of sites other than the small intestine, in this case the bile ducts of guineafowls (Smyth \& McManus 1989). Junker \& Boomker (2007a) have reported immature stages of this parasite from the liver/bile ducts and adults from the small intestine of Helmeted Guineafowls. Whether morphological changes, such as the size of the bile ducts, or biochemical changes, such as the bile composition, during the ontogenesis of the guineafowl hosts in some way facilitate the migration and establishment of developing $P$. paronai has to remain speculation. On the other hand, a change in the prey preference in growing birds, possibly taking larger prey items not formerly included in the diet, may expose older guineafowls to a wider range of parasites.

The significantly higher abundance of Subulura sp. in juvenile birds can be attributed to the fact that the population of Subulura spp. in these hosts was mainly represented by infective larvae that do not yet display sufficient diagnostic characters to distinguish between the two species $S$. dentigera and $S$. 
suctoria. We consider this a result of the fact that infections in the juvenile hosts had been recently acquired, thus comprising a high number of immatures, as opposed to the more mature infections found in older guineafowls.

Host gender was another determinant that had no significant influence on the distribution of worm burdens and species richness within the guineafowl population from Musina. Similar results were obtained by Crowe (1977), who attributed the absence of sexual variation in helminth infections to the fact that there is little behavioural or dietary difference between sexes outside the breeding season. All hosts in our and also Crowe's (1977) study were collected during the non-breeding season, extending from March to October in South Africa (Del Hoyo et al. 1994). Helmeted Guineafowls collected in the Free State Province during August 2007, however, showed sex related differences regarding the intensities of some helminths (Davies et al. in preparation). Possible reasons for this given by the latter authors are a difference in the length of the small intestine and caeca between males and females, as demonstrated by Prinsloo (2003), resulting in a larger habitat in the females. Moreover, females have a relatively higher intake of insects prior to breeding, which is often aided by the male's foraging for its mate (Hockey, Dean \& Ryan 2005).

When discussing helminth communities in avian hosts, Bush (1990) concluded that host age and sex played a minor role, whereas the overall environment and habitat diversity therein exercised a major influence on the patterns of helminth communities. He argued that the latter would directly influence the "supply" of helminths available in the system. Keeping in mind that the current set of data was based on a limited number of hosts, and that a larger sample size might change the emerging picture, it nevertheless suggests that Helmeted Guineafowls are no exception to this general pattern.

\section{ACKNOWLEDGEMENTS}

We thank Dr W.J. Luus-Powell and Mr H.E. Hattingh, University of Limpopo, for providing logistic support to collect the guineafowls, and $\mathrm{Mr} \mathrm{K}$. Meyer and $\mathrm{Mr}$ M. Storm for making the latter available to us. Mr R. Watermeyer, University of Pretoria, is thanked for his assistance with the processing of the cestodes. Ms R. Owen, University of Pretoria, has greatly assisted with the statistical analyses. This study was made possible by a University of Pretoria Postdoctoral Fellowship grant to the first author.

\section{REFERENCES}

ACKERT, J. \& REID, W. 1937. Age resistance of chickens to the cestode Raillietina cesticillus (Molin). Journal of Parasitology, 23:558-563.

ACOCKS, J.P.H. 1988. Veld types of South Africa, with accompanying veld type map (Memoirs of the Botanical Survey of South Africa, No. 57).

ALEXANDER, S. \& McLAUGHLIN, J.D. 1997. A comparison of the helminth communities in Anas undulata, Anas erythrorhyncha, Anas capensis and Anas smithii at Barberspan, South Africa. Onderstepoort Journal of Veterinary Research, 64:161-173.

ANDERSON, R.C. 1992. Nematode parasites of vertebrates, their development and transmission, $1^{\text {st }}$ ed. Wallingford and New York: CABI Publishing.

BIESTER, H.E. \& SCHWARTE, L. (Eds). 1959. Diseases of poultry. Ames: lowa State College Press.

BUSH, A.O., LAFFERTY, K.D., LOTZ, J.M. \& SHOSTAK, A.W. 1997. Parasitology meets ecology on its own terms: Margolis et al., revisited. Journal of Parasitology, 83:575-583.

BUSH, A.O. 1990. Helminth communities in avian hosts: determinants of pattern, in Parasite communities: patterns and processes, edited by G.W. Esch, A.O. Bush \& J.M. Aho. London \& New York: Chapman \& Hall.

BUSH, A.O. \& HOLMES, J.C. 1986a. Intestinal helminths of lesser scaup ducks: patterns of association. Canadian Journal of Zoology, 64:132-141.

BUSH, A.O. \& HOLMES, J.C. 1986b. Intestinal helminths of lesser scaup ducks: an interactive community. Canadian Journal of Zoology, 64:142-152.

CROWE, T.M. 1977. Variation in intestinal helminth infestation of the Helmeted guinea-fowl. South African Journal of Wildlife Research, 7:1-3.

CROWE, T.M. 2000. Helmeted Guineafowl, in Gamebirds of Southern Africa, edited by R.M. Little \& T.M. Crowe. Cape Town: Struik Publishers.

DAVIES, R.O., JUNKER, K., JANSEN, R., CROWE, T.M. \& BOOMKER, J. Age and sex based variation in intestinal helminth infection of Helmeted Guineafowl, Numida meleagris, with comments on the infection of Swainson's Spurfowl, Pternistis swainsonii, and Orange River Francolin, Scleroptila levaillantoides (in preparation).

DEL HOYO, J., ELLIOT, A. \& SARGATAL, J. (Eds.). 1994. Handbook of the birds of the world. Volume 2, New World vultures to guineafowl. Barcelona: Lynx Edicions.

DOGIEL, J.B. 1964. General parasitology. Edinburgh \& London: Oliver \& Boyd.

ESCH, G.W., SHOSTAK, A.W., MARCOGLIESE, D.J. \& GOATER, T.M. 1990. Patterns and processes in helminth parasite communities: an overview, in Parasite communities: patterns and processes, edited by G.W. Esch, A.O. Bush \& J.M. Aho. London \& New York: Chapman \& Hall.

FORRESTER, D.J., CONTI, J.A., BUSH, A.O., CAMPBELL, L.D. \& FROHLICH, R.K. 1984. Ecology of helminth parasitism of bobwhites in Florida. Proceedings of the Helminthological Society of Washington, 51:255-266.

GIBBONS, L.M., JONES, A. \& KHALIL, L.F. 1996. Eighth international training course on identification of helminth parasites of economic importance. St. Albans: International Institute of Parasitology, Commonwealth Agricultural Bureaux. 
GWYUN, A.M. \& HAMILTON, A.G. 1935. Occurrence of a larval cestode in the Red Locust Nomadacris septem fasciata. Parasitology, 27:551-555.

HAIR, J.D. 1975. The structure of the intestinal helminth communities of lesser scaup (Aythya affinis). Ph.D. thesis, University of Alberta.

HOCKEY, P.A.R., DEAN, W.R.J. \& RYAN, P.G. (Eds). 2005. Roberts-Birds of Southern Africa, VIt th edition. Cape Town: The Trustees of the John Voelcker Bird Book Fund.

HODASI, J.K.M. 1969. Comparative studies on the helminth fauna of native and introduced domestic fowls in Ghana. Journal of Helminthology, 43:35-52.

HODASI, J.K.M. 1976. The helminth parasites of the helmet guinea fowl (Numida meleagris galeata Pallas) in Ghana. Bulletin of Animal Health and Production in Africa, 24:8187.

HOLMES, J.C. \& PRICE, P.W. 1986. Communities of parasites, in Community Ecology: Pattern and Process, edited by $\mathrm{J}$. Kikkawa \& D.J. Anderson, Melbourne: Blackwell Scientific Publications.

HORAK, I.G. \& BOOMKER, J. 2000. Parasites of non-domestic mammals, in Wildlife, ostrich and crocodile health. Department of Veterinary Tropical Diseases, University of Pretoria.

JONES, M.F. 1933. Notes on cestodes of poultry. Journal of Parasitology, 20:66.

JUNKER, K. \& BOOMKER, J. 2006. Mediorhynchus gallinarum (Acanthocephala: Gigantorhynchidae) in Helmeted guineafowls, Numida meleagris, in the Kruger National Park, South Africa. Onderstepoort Journal of Veterinary Research, 73: 283-292.

JUNKER, K. \& BOOMKER, J. 2007a. Helminths of guineafowls in the Limpopo Province, South Africa. Onderstepoort Journal of Veterinary Research, 74:265-280.

JUNKER, K. \& BOOMKER, J. 2007b. A check list of the helminth parasites of guineafowl (Numididae). Onderstepoort Journal of Veterinary Research, 74:315-337.

KENNEDY, C.R., BUSH, A.O. \& AHO, J.M. 1986. Patterns in helminth communities: why are birds and fish different? Parasitology, 93:205-215.

LOTZ, J.M. \& FONT, W.F. 1994. Excess positive association in communities of intestinal helminths of bats: a refined null hypothesis and a test of the facilitation hypothesis. Journal of Parasitology, 80:398-413.

MARGOLIS, L., ESCH, G.W., HOLMES, J.C., KURIS, A.M. \& SCHAD, G.A. 1982. The use of ecological terms in parasitology (report of an ad hoc committee of the American Society of Parasitologists). Journal of Parasitology, 56:436-439.

McCULLOCH, C.E. 1985. Variance test for species association. Ecology, 66:1676-1681.

MENTIS, M.T., POGGENPOEL, B. \& MAGUIRE, R.R.K. 1975. Food of Helmeted guieafowl in highland Natal. Journal of the southern African Wildlife Management Association, 5:23-25.

MOHLER, J.R. 1936. Report of the Chief of the Bureau of Animal Industry, 1935-1936. US Department of Agriculture.

MOORE, D.V. 1962. Morphology, life history and development of the acanthocephalan Mediorhynchus grandis Van Cleave, 1916. Journal of Parasitology, 48:76-86.
MOORE, J., FREEHLING, M., HORTON, D. \& SIMBERLOFF, D. 1987. Host age and sex in relation to intestinal helminths of bobwhite quail. Journal of Parasitology, 73:230-233.

ORTLEPP, R.J. 1937. South African helminths. Part I. Onderstepoort Journal of Veterinary Science and Animal Industry, 9:311-336.

ORTLEPP, R.J. 1938a. South African helminths. Part III. Some mammalian and avian cestodes. Onderstepoort Journal of Veterinary Science and Animal Industry, 11:23-50.

ORTLEPP, R.J. 1938b. South African helminths. Part V. Some avian and mammalian helminths. Onderstepoort Journal of Veterinary Science and Animal Industry, 11:63-104.

ORTLEPP, R.J. 1963. Observations on cestode parasites of guinea-fowl from southern Africa. Onderstepoort Journal of Veterinary Research, 30:95-118.

PENCE, D.B. 1990. Helminth community of mammalian hosts: concepts at the infracommunity, component and compound community levels, in Parasite communities: Patterns and processes, edited by G.W. Esch, A.O. Bush \& J.M. Aho. London \& New York: Chapman \& Hall.

PETNEY, T.N., VAN ARK, H. \& SPICKETT, A.M. 1990. On sampling tick populations: The problem of overdispersion. Onderstepoort Journal of Veterinary Research, 57:123-127.

PIELOU, E.C. 1974. Population and community ecology. Principles and methods. New York: Gordon \& Breach, Science Publishers, Inc.

PRINSLOO, H.C. 2003. An investigation into factors influencing the abundance of Helmeted Guineafowl (Numida meleagris) in the Riemland of the North-Eastern Free State, South Africa. M.Tec. dissertation. Technikon Pretoria.

REID, W.M. 1962. Chicken and turkey tapeworms. Handbook to aid in the identification and control of tapeworms found in the United States of America. Poultry Department and Poultry Disease Research Center, College Experiment Station, Athens, Georgia.

RIGGS, M.R. \& ESCH, G.W. 1987. The suprapopulation dynamics of Bothriocephalus acheilognathi in a North Carolina cooling reservoir: abundance, dispersion and prevalence. Journal of Parasitology, 73:877-892.

SAAYMAN, J. 1966. A study of the diet and parasites of Ardeola (Bubulcus) ibis, Numida meleagris and Gallus domesticus from the Eastern Cape Province, South Africa. Ph.D. thesis, University of South Africa.

SCHLUTER, D. 1984. A variance test for detecting species associations, with some example applications. Ecology, 65: 998-1005.

SIEGFRIED, W.R. 1966. Growth, plumage development and moult in the Crowned Guineafowl Numida meleagris coronata Gurney. Department of Nature Conservation Investigational Report, no. 8.

SMYTH, J.D. \& McMANUS, D.P. 1989. The physiology and biochemistry of cestodes. Cambridge: University Press.

SOULSBY, E.J.L. 1969. Helminths, arthropods and protozoa of domesticated animals. London: Bailliere, Tindall and Cassell.

VERSTER, A. \& PTASINSKA-KLORYGA, Y. 1987. Helminths of Helmeted guineafowl in southern Africa. South African Journal of Wildlife Research, Supplement I: 36-38. 